\title{
Biology of Amblyomma aureolatum (Pallas, 1772) (Acari: Ixodidae) on Some Laboratory Hosts in Brazil
}

\section{Daniel Sobreira Rodrigues, Henrique Ávila de Carvalho, André Almeida Fernandes, Carolina Maria Viana Freitas, Romário Cerqueira Leite, Paulo Roberto de 0 liveira+}

\author{
Departamento de Medicina Veterinária Preventiva, Escola de Veterinária, Universidade Federal de Minas Gerais, Av. Antônio \\ Carlos 6627, 30123-970 Belo Horizonte, MG, Brasil
}

The ixodid Amblyomma aureolatum is suspected to play a role in the epidemiology of wild life-cycle hemoparasites, which frequently infect dogs in rural and hunting areas in Brazil. Little is known about its bionomics. The objective of the present study was to evaluate some bionomic aspects of A. aureolatum ticks in Brazil. One engorged female, collected from a dog (Canis familiaris) in São Sebastião das Águas Claras, State of Minas Gerais, was used to establish a colony in the laboratory. Subsequently its parasitic stage progeny were fed on domestic dogs and laboratory animals. The free-living stages were incubated at $27^{\circ} \mathrm{C} \pm 2^{\circ} \mathrm{C}$ and minimum $70 \%$ relative humidity in a $B O D$ incubator. The egg incubation period ranged from 31 to 34 days; the parasitic period of larvae ranged from 4 to 6 days and ecdysis to nymphs occurred from day 19 up to day 22. The parasitic period of nymphs ranged from 5 to 8 days and the period of ecdysis to adults from 31 to 33 days. The parasitic period of adults ranged from 11 to 15 days, the pre-oviposition period from 6 to 12 days, and the oviposition period from 9 to 38 days. The total duration of the life cycle ranged from 116 to 168 days.

Key words: Amblyomma aureolatum - life cycle - dogs - biology - Brazil

According to Aragão and Fonseca (1961), Amblyomma aureolatum was first described by Pallas (1772) in a study carried out in the State of Rio de Janeiro, Brazil. Years later, Koch (1844) described the same species of tick as A. striatum. The description given by Pallas was subsequently disregarded, Koch's description prevailing up to 1961 when Aragão and Fonseca (1961) concluded that both descriptions referred to the same species. Since then, the terminology proposed by Pallas has been adopted, as it preceeded Koch's description by more than 70 years. Aragão $(1911,1936)$ also made basic considerations regarding the morphology and the geographical distribution of A. aureolatum. Fonseca (1935) evaluated the viability and the biological cycle of $A$. aureolatum ticks under natural conditions in Brazil.

Adult stages of $A$. aureolatum have been frequently found on domestic dogs (Canis familiaris) (Fonseca 1935, Evans et al. 2000). Rohr (1909), Aragão (1936), and Aragão and Fonseca (1961) described as possible hosts some wild animals, such as wild canidae (C. azarae and Dusicyon sp.), wild cats (Felis wiedi wiedi), foxes [D. (Cerdocyon) thous entrerianus], crab-eating raccoons (Procyon cancrivorus nigripes), ferrets (Grison furax and G. vittatus brasiliensis), sloth (Bradypus tridactylus), mountain lions [F. (Puma) concolor], deer (Cervus sp., C. paludosus, and Mazama sp.), opossums (Didelphis aurita), capybaras (Hydrochaeris hydrochaeris), the wild rodent Eury-

This study was sponsored by CNPq (Conselho Nacional de Desenvolvimento Científico e Tecnológico), Brazil.

${ }^{+}$Corresponding author and study supervisor.

Fax: +55-31-3499.2080. E-mail: proliver@ vet.ufmg.br

Received 5 December 2001

Accepted 10 June 2002 zygomatomys spinosus catellus (during its nymph stage) and coatis (Nosua socialis). Other domestic animals can also be infested. These include domestic cats ( $F$. catus), goats (Capra hircus), horses (Equus cabalus), pigs (Sus scrofa) and cattle (Bos taurus).

According to recent reports (Fonseca et al. 1996, Nowak 1999), the specific name azarae had already been used to refer to two different species of canidae in Brazil: Lycalopex vetulus and Cerdocyon thous. F. wiedi wiedi, known in Brazil as "maracajá" cat, is nowadays considered to be Leopardus wiedii; foxes are known as C. thous; the genus Dusicyon is nowadays known in Brazil as Cerdocyon; ferrets are Galictis cuja and G. vittata; F. (Puma) concolor is Puma concolor; E. spinosus catellus is cited as E. spinosus; the species $N$. socialis corresponds to $N$. nasua, while $C$. paludosus corresponds to Blastocerus dichotomus. The genus Cervus has not been used in Brazil (Fonseca et al. 1996, Nowak 1999).

The occurrence of A. aureolatum ticks has been reported in all geographical regions of Brazil and in Argentina, Paraguay, Colombia and French Guyana (Aragão 1936, Aragão \& Fonseca 1961, Evans et al. 2000).

A. aureolatum ticks are frequently found infesting dogs in rural areas in Brazil. Considering its ability to infest human beings and wild animals and its capacity to transmit rickettsias (Aragão 1936), A. aureolatum ticks may play an important role in the transmission of rickettsial infections, such as the Rocky Mountain Spotted Fever in Brazil. The objective of the present study was to evaluate some bionomic aspects of different stages of $A$. aureolatum ticks.

\section{MATERIALS AND METHODS}

A survey was carried out in rural areas of the State of Minas Gerais and the dogs living in those areas were examined for the presence of ectoparasites. Every specimen 
found was manually collected from its host, placed into labelled flasks, and taken to the laboratory for identification. In order to obtain naturally detached engorged female ticks, a dog, from São Sebastião das Águas Claras, naturally infested with two females and three males of $A$. Aureolatum, was kept in a cage. The cage was isolated using a double-faced adhesive tape. The dog was infested with 6 other adult stages of $A$. aureolatum ( 3 males and 3 females) that had been collected from dogs living in the same region. Among these ticks, only one female and one male fixed and among all ticks (including the natural and the artificial infestations) only one engorged female was recovered. The engorged female was weighed and placed in a Petri dish for incubation at $27 \pm 1{ }^{\circ} \mathrm{C}$ and minimum $70 \%$ relative humidity in a BOD incubator. These incubation conditions were used throughout the experimental period for the development of all non-parasitic stages of $A$. aureolatum. At the end of the ovipositon period, the eggs were weighed, divided into three groups (group $1=288$ $\mathrm{mg}$; group $2=291 \mathrm{mg}$; group $3=527 \mathrm{mg}$ ) and placed into disposable plastic syringes which were sealed with hydrophilic cotton and incubated. After eclosion, larvae were kept in the incubator during 21 days. Larvae from group 1 were used to infest a guinea pig (Cavia porcellus) while larvae from group 2 were used to infest a rooster (Gallus gallus) and larvae from group 3 were used to infest a 60day old female domestic dog (C. familiaris). The infested hosts were kept in cages, which were placed on metal plates surrounded by double-faced adhesive tape. The recovered engorged larvae were maintained in Petri dishes and incubated. After ecdysis, nymphs were maintained up to 37 days in the incubator and were used to infest two other dogs of approximately 60 days of age. In order to minimize losses, the stages from egg up to non-engorged nymph were not manipulated for quantification. The recovered engorged nymphs were counted, kept in Petri dishes in a BOD incubator until ecdysis to adults. These were counted and identified as males or females. The adult specimens were maintained under incubation conditions up to 31 days, when 40 of them were used to infest a female dog of approximately 4 months of age. A further 24 adult specimens were used to infest a rabbit (Oryctolagus cunicullus) and 24 to infest a rooster (G. gallus). The infestations were carried out, keeping the proportion of $1: 1$ (male/female), in the ears and on the neck in the case of the dog and the rabbit, or under the wings in the case of the rooster. The animals were inspected twice a day (early in the morning and late in the afternoon) for collection of detached ticks. The recovered engorged females were weighed, placed in Petri dishes, and kept under incubation conditions for oviposition. In order to estimate the number of eggs per gram of mass produced, 100 eggs from 10 different ovipositions were weighed and the mean weight was calculated. At the end of the oviposition period the egg masses produced were weighed, placed into plastic syringes that were sealed with hydrophilic cotton and incubated. In order to evaluate embryonic development, eggs were examined under a stereoscopic microscope. The females were kept in Petri dishes and were observed daily to register the moment of death, which was determined by cuticule darkness, dehydration and lack of reaction when they were touched on the legs with a stilette.

The efficiency rates of female ticks in converting their food reservoir to eggs (ERCE) was calculated, according to Szabó (1995), taking into account the weight of egg mass (EW) and weight of engorged females (FW), as follows:

$$
\mathrm{ERCE}=\frac{\mathrm{EW} \times 100}{\mathrm{FW}}
$$

\section{RESULTS}

Adult specimens of A. aureolatum were collected from the end of Autumn (May 15th) to the end of Spring (November 15th) from dogs living in the following areas of State of Minas Gerais, São Sebastião das Águas Claras ( $20^{\circ} 02^{\prime} \mathrm{S}, 43^{\circ} 56^{\prime} \mathrm{W}$, altitude $1,077 \mathrm{~m}$ ), Lavras Novas ( $20^{\circ} 27^{\prime} \mathrm{S}$, $43^{\circ} 33^{\prime} \mathrm{W}$, altitude $1,273 \mathrm{~m}$ ), Ouro Preto ( $20^{\circ} 24^{\prime} \mathrm{S}, 43^{\circ} 30^{\prime} \mathrm{W}$, altitude $1,196 \mathrm{~m})$, Serra do Cipó (19 $19^{\circ} 17^{\prime} \mathrm{S}, 43^{\circ} 35^{\prime} \mathrm{W}$, altitude $1,223 \mathrm{~m}$ ) and Taboleiro (19 03 ' $\mathrm{S}, 43^{\circ} 32^{\prime} \mathrm{W}$, altitude $895 \mathrm{~m}$ ). These areas have a rainy temperate climate, with mean temperature of $18^{\circ} \mathrm{C}$ during the coldest month and $22^{\circ} \mathrm{C}$ during the warmest month and an annual precipitation over $1,200 \mathrm{~mm}$. These conditions are typical of mountainous areas of central and southern regions of Minas Gerais (Antunes 1986). No A. aureolatum ticks were found on dogs living in the cities with no access to the bush.

Most females that had been collected and incubated with the aim of establishing a colony in the laboratory did not undergo ovipositon, even though they had intact mouthparts. Therefore, a single female had to be used for this purpose.

The egg incubation period ranged from 31 to 34 days. The parasitic period of larvae varied from 4 to 6 days and ecdysis to nymphs occurred from day 19 up to day 22 . Although recovery of larvae was not registered in the present study, it was possible to observe that they were able to feed satisfactorily on the various types of hosts tested. The parasitic period of nymphs varied from 5 to 8 days, with 554 engorged nymphs being recovered. The period of ecdysis to adults varied from 31 to 33 days. Among 554 nymphs, 465 underwent ecdysis, resulting 238 males and 227 females. Thus, the index of ecdysis was $83.5 \%$ with $51 \%$ males and $49 \%$ females. Among the 20 A. aureolatum females used to infest the female dog, 18 engorged and one semi-engorged females were recovered (90\% recovery). In contrast, only one engorged female was recovered ( $8.3 \%$ recovery) among the 12 females used to infest the rabbit, and only one semi-engorged female was recovered ( $8.3 \%$ recovery) among the 12 used to infest the rooster.

In the infestation carried out on the female dog, adult specimens of A. aureolatum fixed on the back, neck, head, ears, and interdigital membranes. The parasitic period of adults varied from 11 to 15 days, the pre-oviposition period from 6 to 12 days, the oviposition period from 9 to 38 days and survival of females after the oviposition period ranged from 2 to 27 days.

The mean weight of 18 recovered engorged females (disregarding semi-engorged females) was $787.8 \mathrm{mg}$ and the mean weight of egg masses produced was $303.75 \mathrm{mg}$. 
The mean number of eggs produced per gram was 15,151 . The mean ERCE was 37\%. One semi-engorged female did not undergo oviposition and three engorged females, originated from the dog, laid darkened and dehydrated eggs, which were not viable. The other 16 females produced brilliant light yellow eggs with embryonic development, but these became dehydrated within 15 days of incubation. The total duration of the biological cycle of $A$. aureolatum tick (disregarding the period that each stage is able to survive without feeding) ranged from 116 to 168 days (Table).

\section{TABLE}

Biological parameters of Amblyomma aureolatum ticks under laboratory conditions $\left(27 \pm 1^{\circ} \mathrm{C}, 70 \% \mathrm{RH}\right.$ and scotophase $)$

\begin{tabular}{lcc}
\hline Biological parameter & $\begin{array}{c}\text { Mean } \pm \text { standard } \\
\text { deviation }\end{array}$ & $\begin{array}{c}\text { Variation } \\
\text { width }\end{array}$ \\
\hline Larval parasitic period (days) & - & 4 to 6 \\
Ecdysis to nymph period (days) & - & 19 to 22 \\
Nymph parasitic period (days) & $6.42 \pm 0.58$ & 5 to 8 \\
Ecdysis to adult period (days) & $32.07 \pm 0.56$ & 31 to 33 \\
Female engorging period (days) & $12.35 \pm 1.39$ & 11 to 15 \\
Pre-oviposition period (days) & $9.53 \pm 1.90$ & 6 to 12 \\
Oviposition period (days) & $23.19 \pm 6.79$ & 9 to 38 \\
Egg incubation period (days) & - & 31 to 34 \\
Post-oviposition longevity & $5.56 \pm 6.37$ & 2 to 27 \\
period (days) & - & 116 to 168 \\
Total life cycle period (days) & & \\
Weight of engorged females (mg) & $787.79 \pm 318.83$ & 363 to 1730 \\
Weight of egg mass (mg) & $303.75 \pm 262.12$ & 45 to 1106 \\
ERCE (\%) & $37 \pm 14$ & 12 to 64 \\
\hline
\end{tabular}

ERCE: efficiency rates of female ticks in converting their food reservoir to eggs.

\section{DISCUSSION}

Fonseca (1935), evaluating 11 females of $A$. aureolatum, under natural conditions (temperatures from 24 to $25^{\circ} \mathrm{C}$ ), obtained the following parameters: the pre-oviposition period ranged from 8 to 11 days, the oviposition period from 16 to 26 days, the egg incubation period from 50 to 52 days (including the oviposition period), the parasitic stage of larvae from 3 to 4 days, ecdysis from larva to nymph from 18 to 26 days, the parasitic stage of nymphs from 5 to 7 days, ecdysis from nymph to adult from 31 to 36 days, a proportion of 1 male for each 3 females, the parasitic stage of females of 11 days and the total duration of the life cycle of 107 days. It appears that Fonseca did not consider the parasitic stage of females and the pre-oviposition period, as the sum of the values does not coincide with the duration of the mentioned cycle. The sum of these values indicates a minimum duration of 126 days and a maximum duration of 147 days.

Fonseca (1935) also observed that females were dead 7 to 8 days after the end of the oviposition period. These values disagree with the results obtained in the present study, in which females died, on average, 5.56 days (modal day equals 2) after oviposition had finished. Partially engorged females and females laying few eggs had longer periods of survival. In both studies, the oviposition process was irregular, with frequent 1- to 3 -day intervals with no eggs being laid. The weights of fully engorged females (from 864 to $1,590 \mathrm{mg}$ ) and egg masses (from 383 to 740 $\mathrm{mg}$ ) reported by Fonseca were higher than the mean weight of engorged females (787.8 mg) and egg mass (303.7 $\mathrm{mg}$ ) estimated in the present study. Only one engorged female produced egg mass heavier than $320 \mathrm{mg}$ (egg mass weight $=1,106 \mathrm{mg}$ ). All engorged females evaluated by Fonseca had been collected from hosts under natural conditions. The lower weight of engorged females and egg masses obtained in the present study suggest that the experimental incubation conditions were not appropriate to fulfill the requirements of this species of ixodide. The lack of egg hatching may also be related to the incubation conditions used. The regions in which $A$. aureolatum ticks have been reported usually present a temperate and humid climate. This fact suggests that lower temperatures and higher relative humidity conditions should be considered in attempts to maintain a laboratory colony of $A$. aureolatum.

Although the Petri dishes had been sterilized and the incubator fumigated ( 40 volumes formalin $+\mathrm{KMnO}_{4}$ ), fungal contamination was observed during ecdysis from nymph to adult and during the oviposition period of engorged females. Contamination did not appear to affect ecdysis to adult, as more than $80 \%$ of the specimens were able to complete it. Contamination caused some egg losses ( 6 out of 16 egg masses produced were contaminated by fungus and 3 of them were discarded) and, may have, affected female post-oviposition longevity since all females were contaminated. The type of contaminating fungi was not identified.

As far as the duration of each stage of the life cycle is concerned, the results observed in both studies were very similar although the values obtained in the present study showed greater amplitude.

\section{ACKNOWLEDGEMENT}

To Mr Adriano Pereira Paglia (Laboratório de Mastozoologia e Controle Ambiental, Instituto de Ciências Biológicas, UFMG) for his valuable collaboration on the taxonomic classification of mammals.

\section{REFERENCES}

Antunes FZ 1986. Caracterização climática do estado de Minas Gerais. Inf Agropecuário 12: 9-13.

Aragão HB 1911. Notas sobre ixódidas brasileiros. Mem Inst Oswaldo Cruz 3: 145-195.

Aragão HB 1936. Ixodidas brasileiros e de alguns países limítrofes. Mem Inst Oswaldo Cruz 31: 759-846.

Aragão HB, Fonseca F 1961. Notas de ixodologia. IX. O complexo ovale do gênero Amblyomma. Mem Inst Oswaldo Cruz. 59: 131-148.

Evans DE, Martins JR, Guglielmone AA 2000. A review of the ticks (Acari, Ixodida) of Brazil, their hosts and geographic distribution - 1. The State of Rio Grande do Sul, Southern Brazil. Mem Inst Oswaldo Cruz 95: 453-470.

Fonseca F 1935. Validade da espécie e ciclo evolutivo de Amblyomma striatum Koch, 1844 (Acarinae, Ixodidae). Mem Inst Butantan 9: 19-51.

Fonseca GAB, Herrmann G, Leite YLR, Mittermeier RA, Rylands AB, Patton JL 1996. Lista Anotada dos Mamíferos 
856 A. aureolatum on Laboratory Hosts - Daniel Sobreira Rodrigues et al.

do Brasil. Occasional Papers in Conservation Biology, Conservation International \& Fundação Biodiversitas, USA $20 \mathrm{pp}$.

Nowak RM 1999. Walker's Mammals of the World, 6th ed., The Johns Hopkins University Press, Baltimore and London, 1986 pp.
Rohr CJ 1909. Estudos sobre Ixodidae do Brasil, Instituto Oswaldo Cruz, Rio de Janeiro, 220 pp.

Szabó MPJ, Mukai LS, Rosa PCS, Bechara GH 1995. Differences in the acquired resistance of dogs, hamsters, and guinea pigs to repeated infestations with adult ticks Rhipicephalus sanguineus (Acari: Ixodidae). J Vet Res Anim Sci 32: 43-50. 